\title{
Research on Supercritical Methanol Treatment of Lignite
}

\author{
Haiyan Luan ${ }^{1,2}$, Aiguo Wang, ${ }^{2,3}$ Qian Zhang ${ }^{2,3}$, Fuming Chen ${ }^{2,3}$ \\ ${ }^{1}$ Dept. of Chemical Engineering, Tsinghua University, Beijing, China \\ ${ }^{2}$ Research Institute of Tsinghua University in Shenzhen, Shenzhen, China \\ ${ }^{3}$ Shenzhen Key Lab of Separation Technology, Shenzhen, China \\ Email: luanhaiyancumt@126.com, Wangag@tsinghua-sz.org
}

Received 2012

\begin{abstract}
China has rich lignite reserves which are the proper resources to be liquefied. As its low coalification degree, much hydrogen is wasted. Solvent extraction can save hydrogen and improve its liquefaction performance. The paper studies supercritical methanol treatment of lignite with a device at high temperature and pressure. Experiments mainly focus on the effects of temperature, pressure, catalysts and pretreatment ways on the extraction rate. Results indicate that the extraction rate increases with raising of temperature and pressure below $330^{\circ} \mathrm{C}, 10 \mathrm{MPa}$. When temperature exceeds $330^{\circ} \mathrm{C}$, extraction rate decreases slightly. After swelling pretreatment in methanol for $8 \mathrm{~h}$, the lignite is treated for $60 \mathrm{~min}$ at $330^{\circ} \mathrm{C}, 8.2 \mathrm{MPa}$ with $\mathrm{NaOH}$ as catalyst(1\%wt). The weight ratio of methanol/ Xilinhaote lignite is $5 / 1$. Under these conditions, the extraction rate can reach $22.88 \%$.
\end{abstract}

Keywords: Lignite; Supercritical Methanol Treatment; Extraction Rate

\section{Introduction}

Lignite reserves cover $13 \%$ of all the coal reserves in China. As its rich reserves and fine liquefaction behavior, lignite becomes high-quality resource to be liquefied. But expensive hydrogen is wasted because water is formed during liquefaction process[1,2]. To treat lignite before liquefaction can help save hydrogen, improve the reactivity of lignite and increase oil yield during liquefaction[3]. Therefore, the pretreatment is of an important significance for its comprehensive utilization.

Solvent extraction of coal is a hot topic because it can study coal structure and get small molecule compounds. Li et al[4] did researches on the relationship of the extraction rate of ashfree coal and extraction temperature in NMP. Hu et al[5] extracted coal with water under its supercritical and subcritical state. They found that temperature and pressure were important factors which influence the extraction results. High temperature and pressure improve solvent diffusion speed and dissolving power as well exacerbate the resolvability of lignite. Yunus et al[6] studied the extraction performance of about 20 kinds of solvents with Soxhlet extraction. The extraction rate has a close relation with solvent polarity. It shows a higher extraction rate in polar solvents than in nonpolar solvents.

Coal structure and operation conditions are the key to extraction results. Coal is made up of condensation aromatic rings as basic framework and side chains. Basic units are connected with ether bonds and methylene bonds. Side chains include alkyls and other functional groups. There is strong acting force between coal molecules such as interionic force, hydrogen bonds and Van der Waals force[7]. Pretreatment should weaken the acting force between coal molecules and dissolve the extracts[8]. Besides coal structure and solvent properties, factors

${ }^{*}$ High-tech Zones Development Guidance Special of Guangdong Province- Key Problems Tackling and Industrialization Type g(2010A011300038). which influence the speed during mass transfer process include permeation and diffusion [9]. Treatment include two parts. Solvent molecules permeate into coal micro pore structure and then soluble substance spreads outside.

Fluids under supercritical conditions are easier to enter coal molecules and can solve soluble substance better. So the paper adopts supercritical methanol to pretreat lignite. Carbon emission reduces because less $\mathrm{CO}$ and $\mathrm{CO}_{2}$ is produced. Experiments aim at the extraction rate and study the effects of temperature, pressure, catalyst and pretreatment ways on the extraction rate. Optimized technologies lay the foundation for coal liquefaction.

\section{Experiments}

\subsection{Instruments and Reagents}

Main instruments: Sartorius BS2109 electronic scale; RE2000E Rotary Evaporator; FYXD2-20/400 autoclave $\left(\mathrm{T}_{\max }=450, \mathrm{P}_{\max }=\right.$ 20MPa, V=2L); ZDXS3-5-1200 muffle.

Reagents: methanol, tetrahydrofuran, $\mathrm{NaOH}, \mathrm{H}_{2} \mathrm{SO}_{4}$. All the reagents are analytically pure.

\subsection{Lignite Sample}

The coal sample is Xilinhaote lignite from Inner Mongolia. The sample has been grinded and sifted(200 mesh). Proximate and ultimate analysis of the sample is shown in Table 1.

Table 1. Proximate and ultimate analysis of Xilinhaote lignite sample $\left(w_{t} \%\right)$.

\begin{tabular}{cccccccc}
\hline \multicolumn{3}{c}{ Proximate analysis } & \multicolumn{5}{c}{ Ultimate analysis, daf } \\
\hline$M_{\mathrm{ad}}$ & $A_{\mathrm{ad}}$ & $V_{\mathrm{daf}}$ & $C$ & $H$ & $O^{*}$ & $N$ & $S$ \\
9.95 & 10.21 & 47.49 & 65.87 & 5.13 & 27.37 & 1.07 & 0.56 \\
\hline
\end{tabular}

*by difference. 


\subsection{Experiment Methods}

Mix 200 g coal sample, certain methanol and 2 g catalyst into slurry. After swelling for 8 hours, put it into the autoclave. Heat the mixture at rate of $5{ }^{\circ} \mathrm{C} / \mathrm{min}$ and stir it at rate of $200 \mathrm{r} / \mathrm{min}$. Pressure is controlled by the intrant volume of methanol. Treat at a constant temperature for a certain time. Turn on the tap to cold down the system. When the temperature is below $70{ }^{\circ} \mathrm{C}$,take out all the material in the autoclave. Separate the solid and liquid after treatment using vacuum suction filtration. Filter residue is washed three times by methanol and tetrahydrofuran. When it is dried, test its ash content and calculate the extraction rate.

\subsection{Analysis Methods}

Define the mass of dry solid before and after treatment as $M_{1}$, $M_{2}$, ash content as $A_{1}, A_{2}$, extraction rate as $E$. Suppose the weight of ash will not change during the treatment process, so:

$$
\begin{gathered}
M_{1} \cdot A_{1}=M_{2} \cdot A_{2} \\
E=\frac{M_{1}\left(1-A_{1}\right)-M_{2}\left(1-A_{2}\right)}{M_{1}\left(1-A_{1}\right)}
\end{gathered}
$$

According to (1)(2):

$$
E=\frac{A_{2}-A_{1}}{A_{2}\left(1-A_{1}\right)} \times 100 \%
$$

The ash content of the extracts is below $0.1 \%$ by the test. That is all the ash is still in the solid. It is feasible to calculate the extraction rate using the above ash balance method.

\section{Results and Analysis}

\subsection{Effects of Different Treatment Conditions on Extraction Performance}

1) Effect of temperature on extraction performance

Take $\mathrm{H}_{2} \mathrm{SO}_{4}$ and $\mathrm{NaOH}$ as catalyst separately. Treat the lignite for $60 \mathrm{~min}$ at $9.0 \pm 0.5 \mathrm{MPa}$. The weight ratio of methanol: Xilinhaote lignite is $5: 1$. Research the effect of temperature on extraction performance $\left(\mathrm{T}=260-320{ }^{\circ} \mathrm{C}\right)$. The variation of $E$ with $\mathrm{T}$ is shown in Figure 1.

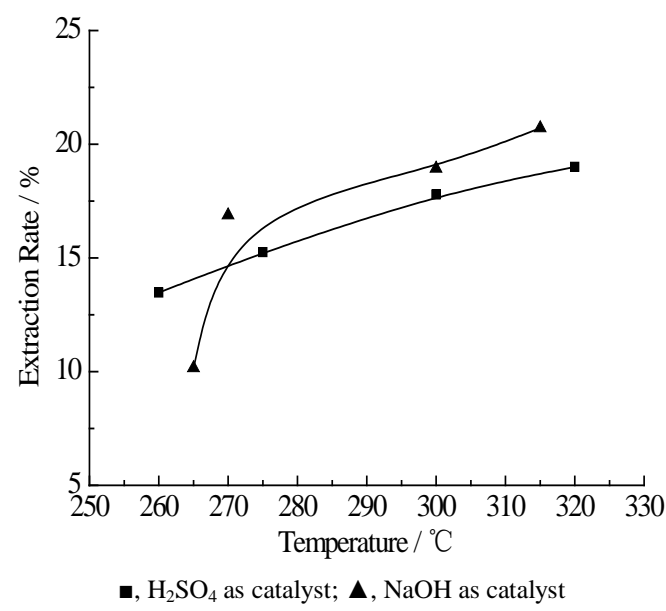

Figure 1. The effect of temperature on $E$.
As is shown in fig1,with the increase of temperature(260-320 $\left.{ }^{\circ} \mathrm{C}\right)$ at certain pressure, $E$ increases obviously no matter the catalyst is sour or basic. At lower temperature, that is near or above the critical temperature of methanol, $\mathrm{H}_{2} \mathrm{SO}_{4}$ is better than $\mathrm{NaOH}$. When temperature surpasses $270^{\circ} \mathrm{C}, \mathrm{NaOH}$ is better than $\mathrm{H}_{2} \mathrm{SO}_{4}$.

With the rise of temperature, solvent viscosity decreases. Solvent molecules are easier to enter macro molecule structure, leading dissociation of ether bonds. The dissociation speed increase with the increasing temperature. Alcohols provide active hydrogen, therefore free radicals and micro molecules can be stable[13,14]. The solubility of compounds in methanol increases. Hence the extraction rate increases with temperature.

2) Effect of pressure on extraction performance

Take $\mathrm{H}_{2} \mathrm{SO}_{4}$ and $\mathrm{NaOH}$ as catalyst separately. Treat the lignite for $60 \mathrm{~min}$ at $260^{\circ} \mathrm{C}$. The weight ratio of methanol/Xilinhaote lignite is $5 / 1$. Research the effect of pressure on extraction performance $\left(\mathrm{T}=260-320^{\circ} \mathrm{C}\right)$. The variation of $E$ with $\mathrm{T}$ is shown in Figure 2.

As is shown in Figure 2, with the increase of pressure at certain temperature, $E$ increases obviously no matter the catalyst is sour or basic. When the pressure surpasses 8.1 MPa, $\mathrm{NaOH}$ is better than $\mathrm{H}_{2} \mathrm{SO}_{4}$.

For supercritical fluids, the increase of pressure means increase of solubility. During supercritical treatment, fluids of high solubility makes free radicals move away from coal subjects. Secondary reactions are avoided. At the same time, high pressure can make fresh solvent permeate into coal molecules. The mass transfer speed is raised because of higher turbulivity. Hence the extraction rate increases with pressure.

3) Effect of catalysts on extraction performance

Acid and base can help damage some strong chemical bonds. Through 2.1.1 and 2.1.2, we can make the conclusion that $\mathrm{NaOH}$ is better than $\mathrm{H}_{2} \mathrm{SO}_{4}$ when pressure surpasses methanol critical pressure and temperature above $270{ }^{\circ} \mathrm{C}$. Oxygen exists in coal in the form of carboxyl, hydroxyl and other functional groups. Carboxyl and hydroxyl are acid groups[16-18]. Base can also enforce hydrolyzation of oxygen bonds and increase the content of hydroxyl[19]. Hence to choose base as catalyst is better for raising extraction rate.

4) Effect of pretreatment ways on extraction performance

All the experiment samples above have been swelled in methanol for $8 \mathrm{~h}$. Pretreatment will influence coal molecule structure. The table below shows the effect of different pretreatment ways on the extraction rate at similar temperature and pressure.

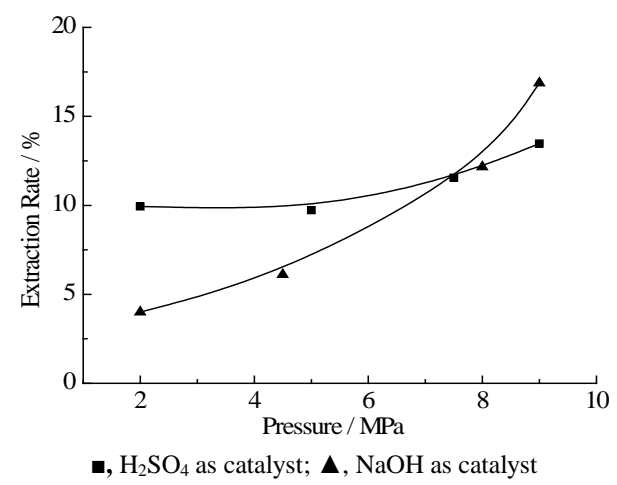

5) Swelling

Figure 2. The effect of pressure on $\mathrm{E}$. 
Compared $1^{\#}$ and $3^{\#}$ in Table 2, after swelling, the extraction rate increases $4.60 \%$ at similar treatment conditions. It is proper to make the conclusion that swelling can help increase the extraction rate.

Swelling can weaken the association between coal macro molecules[20]. New structure makes it easier for solvent molecules to touch coal. What's more, micro molecules enter supercritical fluids. Secondary reactions and reverse reactions can be avoided[21].

6) Effect of moisture in coal

Compared $1^{\#}$ and $2^{\#}$ in Table 2, the extraction rate of $1^{\#}$ is $1.66 \%$ higher than $2^{\#}$, in which the lignite sample is dried. Treatment temperature and catalyst are the same, but treatment pressure of the former is $1 \mathrm{MPa}$ higher than the latter. According to the analysis about the effect of pressure on the extraction rate, suppose treatment pressure was the same extraction rate should be similar to each other. It is difficult for $\mathrm{H}_{2} \mathrm{O}$ as an inorganic solvent to solve long-chain compounds, benzene rings and condensed rings in coal. The supercritical condition of $\mathrm{H}_{2} \mathrm{O}$ is $\mathrm{Tr}=374.3^{\circ} \mathrm{C}, \mathrm{Pr}=22.12 \mathrm{MPa}$. Under the conditions in this paper, $\mathrm{H}_{2} \mathrm{O}$ cannot damage the coal molecules. Compared with large scale of methanol solvent, the effect of moisture in coal can be ignored.

Through the analysis about effects of different experiment conditions on the extraction rate, some conclusions can be drew. To get high extraction rate, we should swell the coal sample, use base as catalyst and make the temperature and pressure above methanol critical point.

\subsection{Further Discussion on Treatment Temperature}

Effects of temperature and pressure on the extraction rate are preliminary investigated through above extraction experiments under different conditions. In fact, pressure of the autoclave is controlled by adjusting the volume of material. Considering that the increase of pressure will bring higher requirement of the equipments and subsequent liquefaction technologies, further studies focus on the extraction rate at higher temperature and pressure of 8.2 MPa. If temperature continues to increase, the weight ratio of solvent/coal will reduce on the basis of the 6:1. Treatment cost can be lower.

The experiment scheme is determined after comprehensive analysis above. Firstly, swell the sample in methanol. With $\mathrm{NaOH}$ as catalyst and pressure controlled at $8.2 \mathrm{MPa}$, increase the temperature gradually from $240^{\circ} \mathrm{C}$, which is methanol critical temperature. When the temperature reaches the test temperature, stabilize for $60 \mathrm{~min}$.

The result can be seen in Figure 3. During the procedure of temperature varies from $260^{\circ} \mathrm{C}$ to $320^{\circ} \mathrm{C}$, the extraction rate increases obviously, which is consistent with the results of the

Table 2. The effect of different pretreatment ways on the extraction rate.

\begin{tabular}{lcccc}
\hline Pretreatment ways & $\boldsymbol{T} /{ }^{\circ} \mathbf{C}$ & $\boldsymbol{P} / \mathbf{M P a}$ & Catalyst & $\boldsymbol{E} / \%$ \\
\hline Original sample $\left(1^{\#}\right)$ & 310 & 10.5 & $1 \% \mathrm{NaOH}$ & 17.87 \\
Only drying $\left(2^{\#}\right)$ & 310 & 9.5 & $1 \% \mathrm{NaOH}$ & 16.21 \\
Swelling $\left(3^{\#}\right)$ & 310 & 9.5 & $1 \% \mathrm{NaOH}$ & 22.47 \\
\hline
\end{tabular}

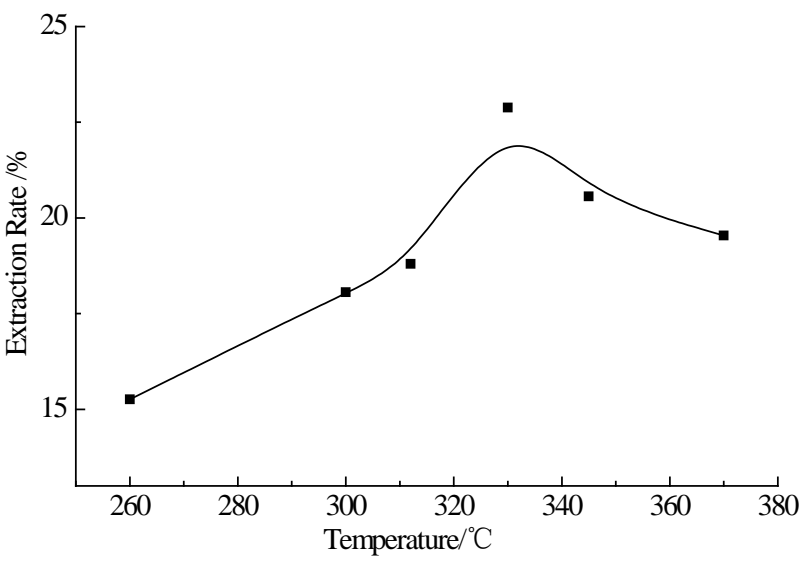

Figure 3. Variation of $E$ with T.

foregoing. When the temperature rises to $330^{\circ} \mathrm{C}$, the extraction rate reaches the maximum. Continuing to rise the temperature to $370^{\circ} \mathrm{C}$, the extraction rate decrease slightly.

The rise of temperature makes the coal pyrolysis accelerating and free radicals generate in a very short period. $\mathrm{H}$-donor ability of methanol $\mathrm{f}$ is limited and free radicals cannot be stable right away. As a part of free radicals poly-condense together, the extraction rate is decreased[13,14]. Therefore, to obtain a higher extraction rate, the reaction temperature should be maintained at about $330^{\circ} \mathrm{C}$.

\section{Conclusions and Prospect}

The extraction rate increases with the raising of temperature and pressure below $330^{\circ} \mathrm{C}, 10 \mathrm{MPa}$ regardless of $\mathrm{NaOH}$ or $\mathrm{H}_{2} \mathrm{SO}_{4}$ as catalyst and reaches its maximum at $330^{\circ} \mathrm{C}$. However, there is a downward trend when continuing to raise temperature. Experiment results show that taking $\mathrm{NaOH}$ as catalyst is more conducive to improve the extraction rate than $\mathrm{H}_{2} \mathrm{SO}_{4}$.

After swelling pretreatment in methanol for $8 \mathrm{~h}$, the lignite is treated for $60 \mathrm{~min}$ at $330^{\circ} \mathrm{C}, 8.2 \mathrm{MPa}$ with $\mathrm{NaOH}$ as catalyst(1\%wt). The weight ratio of methanol/Xilinhaote lignite is $5 / 1$. Under these conditions, the extraction rate can reach $22.88 \%$.

In this paper, the influence factors such as temperature, pressure, catalyst and pretreatment on supercritical methanol processing lignite have been studied. But the analysis and separation for the extracts need further exploration.

\section{REFERENCES}

[1] H. Dai, K. Xie, Technology and Use of Lignite, Peking: Coal Industry,1999, pp. 1-9

[2] M. Satoru, H. Masahiro, K. Koh, Analysis of oxygen-functional groups in brown coals.Fuel Processing Technology, vol. 67, pp. 231-243, 2000.

[3] Z. Shi, Study on Thermal Extraction of Coal and Hydrogenation Liqucfaetion Behavior of Extract, April 2009.

[4] C. Li, T. Takanohashi, T. Yoshida, Effect of acid treatment on thermal extraction yield in ashless coal production, Fuel, vol. 83(3), pp. 727-732, 2004.

[5] O. Yunus, C. Kadim, Low temperature extractability and solvent swelling of Turkish liginites, Fuel Processing Technology, vol. 
53(1-2), pp. 81-97, 1997.

[6] H Hu, S. Guo, K. Hedden. Extraction of lignite with water in sub- and supercritical states, Fuel Processing Technology, vol. 53(3), pp. 269-277, 1997.

[7] K. Xie, Coal Structure And Its Reactivity, Peking: 2002, pp.68-90

[8] C. Chen, J. Gao, X. Wei, Solvent Extraction And Coal Cleaning, Coal Conversion, vol. 18(2), pp. 14-20, 1995.

[9] Y. Tian, S. Shen, Y. Tian, Coal Unfreezing Extraction and Coal Chemical Group Composition, Journal of Taiyuan University of Technology, vol. 32(6), pp. 555-558, 2001.

[10] F Czechowski, M Stolarski, R. Bernd, Supercritical fluid extracts from brown coal litho types and their group components-molecular composition of non-polar compounds, Fuel, vol. 81, pp. 1933-1944, 2002.

[11] T. Yoshida, T. Takanohashi, K. Sakanishi, The effect of extraction condition on “hypercoal” production( I ): Under room-temperature filtration, Fuel, vol. 81(10), pp. 1463-1469, 2002.

[12] J. Shen, X. Li, G. Zou, Extraction yield of different rank coals in $\mathrm{CS}_{2}$-NMP and their relation w ith coals property, Coal Conversion, vol. 28(3), pp. 1-4, 2005.

[13] W. Liu , T. Xia, S. Zhang, X. Wei, Z. Zong , C. Li, Factors influencing supercritical methanolysis of lignite, Journal of Wu- han University of Science and Technology, vol. 33(1), pp. 95-98, 2010.

[14] Z. B. Zhao, S. S. Chen, Z. F. Zhang, Study on Suprcritical Gas Extraction of Coal, Coal Conversion, vol. 19(1), pp. 88-95, 1996.

[15] C. H. Chen, Supercritical Extraction Features Of Some Coals, Coal Conversion, vol. 18(4), pp. 68-74, 1995.

[16] X. Zhu, Z. B. Zhu, C. J. Han, C. F. Zhang, Quantitative Determination Of Oxygen- Containing Functional Groups In Coal By Ftir Spectroscopy, Journal of Fuel Chemistry and Technology, vol. 27(4), pp.335-339, 1999.

[17] M. Li, Research On Oxygen-Containing Functional Groups On Coal Surface, May, 2004.

[18] P. Zhao, S. D. Shi, Research on Forms of Organic Oxygen in Shengli Lignite with XPS, Coal Science and Technology, vol. 32(7), pp. 51-52, 2004.

[19] Y. Chen, J. S. Gao, J. Yan, Extraction of Coal with Cyclohexanone, Journal of Fuel Chemistry and Technology, vol. 25(1), pp. 60-64, 1997.

[20] H. M. Li, Study on the Effect of Pretreatments on coal liquefaction reactivity, May 2010.

[21] H. Q. Hu, H. Qian, S. C. Guo, Solvent Swelling of Coal for Improved Supercritical Extraction, Journal of Fuel Chemistry and Technology, vol. 25(3), pp. 223-226, 1997. 